\title{
Temperature and light effects on Trichobilharzia szidati cercariae with implications for a risk analysis
}

\author{
Azmi Al-Jubury ${ }^{1 *}$ (D) Per Kania ${ }^{1}$, Anette Bygum² and Kurt Buchmann ${ }^{1}$
}

\begin{abstract}
Background: Cercarial dermatitis (swimmer's itch) caused by bird schistosome cercariae, released from intermediate host snails, is a common disorder also at higher latitudes. Several cases were observed in the artificial Danish freshwater Ringen Lake frequently used by the public for recreational purposes. The lake may serve as a model system when establishing a risk analysis for this zoonotic disease. In order to explain high risk periods we determined infection levels of intermediate host snails from early spring to late summer (March, June and August) and elucidated the effect of temperature and light on parasite shedding, behavior and life span.

Results: Field studies revealed no shedding snails in March and June but in late summer the prevalence of Trichobilharzia szidati infection (in a sample of 226 pulmonate Lymnaea stagnalis snails) reached $10 \%$. When investigated under laboratory conditions the cercarial shedding rate (number of cercariae shed per snail per day) was positively correlated to temperature raising from a mean of 3000 (SD 4000) at $7^{\circ} \mathrm{C}$ to a mean of $44,000(\mathrm{SD} 30,000)$ at $27^{\circ} \mathrm{C}$ ). The cercarial life span was inversely correlated to temperature but the parasites remained active for up to $60 \mathrm{~h}$ at $20^{\circ} \mathrm{C}$ indicating accumulation of cercariae in the lake during summer periods. Cercariae exhibited positive phototaxy suggesting a higher pathogen concentration in surface water of the lake during daytime when the public visits the lake.

Conclusion: The only causative agent of cercarial dermatitis in Ringen Lake detected was T. szidati. The infection risk associated with aquatic activities is low during spring and early summer (March-June). In late summer the risk of infection is high since the release, behavior and life span of the infective parasite larvae have optimal conditions.
\end{abstract}

Keywords: Trichobilharzia, Bird schistosomes, Lymnaea stagnalis, Cercaria, Swimmer's itch

\section{Background}

A series of schistosome species within the genus Trichobilharzia use birds (water fowl) as final hosts, carrying the adult stage, and pulmonate snails as intermediate hosts, shedding infective cercariae. These parasites are zoonotic as human may act as accidental host. The cercariae are the causative agent of cercarial dermatitis (swimmer's itch), a skin rash provoked by penetration

\footnotetext{
${ }^{*}$ Correspondence: azmi@sund.ku.dk

${ }^{1}$ Laboratory of Aquatic Pathobiology, Department of Veterinary

and Animal Sciences, Faculty of Health and Medical Sciences, University

of Copenhagen, Stigbøjlen 7, 1870 Frederiksberg C, Denmark

Full list of author information is available at the end of the article
}

of cercariae into the skin. Cercarial dermatitis has been recorded worldwide [1-4] including cold areas at northern latitudes e.g. Denmark [5-7], Norway [8], Sweden [9] and Iceland (geothermally heated water bodies) [2]. Cercarial dermatitis is diagnosed mainly during summer time when both cercarial shedding from snails and recreational activities (bathing, swimming, fishing, sailing) in freshwater bodies are peaking [3, 10-12]. During the warm summer of 2018, several clinical cases were reported among children and adults following bathing in Ringen Lake, Roskilde, Denmark [3]. The lake is frequently visited by residents in the area for swimming and fishing, and may serve as a model system for establishing

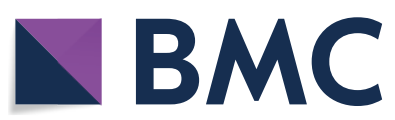

(c) The Author(s) 2020. This article is licensed under a Creative Commons Attribution 4.0 International License, which permits use, sharing, adaptation, distribution and reproduction in any medium or format, as long as you give appropriate credit to the original author(s) and the source, provide a link to the Creative Commons licence, and indicate if changes were made. The images or other third party material in this article are included in the article's Creative Commons licence, unless indicated otherwise in a credit line to the material. If material is not included in the article's Creative Commons licence and your intended use is not permitted by statutory regulation or exceeds the permitted use, you will need to obtain permission directly from the copyright holder. To view a copy of this licence, visit http://creativecommons.org/licenses/by/4.0/. The Creative Commons Public Domain Dedication waiver (http://creativecommons.org/publicdomain/zero/1.0/) applies to the data made available in this article, unless otherwise stated in a credit line to the data. 
a risk analysis. The bird schistosomes within the genus Trichobilharzia spp. reside as adult egg- laying parasites in internal organs (veins of viscera or the nasal mucosa) of the definitive bird host. The eggs release ciliated larvae (miracidia) which are released to the water body and subsequently penetrate the intermediate snail host whereafter asexual development in sporocysts lead to production of cercariae. These are shed into the water ready to penetrate the skin of the definitive host for completion of the life cycle [1]. However, only a few of the cercariae reaches its final or accidental host, because cercariae are directly exposed to and affected by environmental biotic and abiotic factors which may affect survival and life span [13, 14]. We have therefore conducted an analysis of the bird schistomes in the intermediate host snails sampled in the lake from early spring to late summer (March, June and August). As the cercarial dermatitis cases were reported in the summer period [3] it is relevant to elucidate the behaviour of the cercariae in relation to temperature (effect of different temperatures on cercarial shedding and life span) and light (phototaxy). Based on the results we present a risk analysis with recommendations for management of such a lake system and instructions for the public in order to prevent or reduce occurrence of future cercarial dermatitis cases.

\section{Methods}

\section{Location}

Ringen Lake is an artificial freshwater lake (supplied with ground water) located in Roskilde, Denmark $\left(55^{\circ} 37^{\prime} 56.3^{\prime \prime} \mathrm{N} 12^{\circ} 04^{\prime} 55.0^{\prime \prime} \mathrm{E}\right)$. It has a short history, as it was established between 1973 and 1977. It has a surface area just below $10,000 \mathrm{~m}^{2}$, a maximum water depth of $1.5 \mathrm{~m}$ and is used for leisure and recreational purposes. Several species of aquatic plants and animals including invertebrates (snails), fish (roach, perch and pike) and water fowl (ducks and swans) have populated the lake. The water temperature during snail collections in August 2019 was $18-19^{\circ} \mathrm{C}$ at various positions in the lake (measured at a depth of $1 \mathrm{~m}$ ) and the photoperiod $15 \mathrm{~h}$ light and $9 \mathrm{~h}$ darkness.

\section{Collection of snails}

Pulmonate snails (mean shell length and width $44.6 \pm 6.3$ and $22.2 \pm 3.6 \mathrm{~mm}$, respectively) were randomly collected by hand along several parts of the shore in March, June and August of 2019. The samples size in March was low due to the reduced availability of snails in that month (probably associated with the low water temperature at $7{ }^{\circ} \mathrm{C}$ ), while snails were abundant at higher temperatures later in the season (Table 1).

\section{Identification of snails}

After transportation to the Laboratory of Aquatic Pathobiology at the University of Copenhagen, infected snails were identified based on morphometric characters (morphology, shell length and width) [15]. Snails were screened for release of Trichobilharzia sp. cercariae by placing them separately in $400 \mathrm{~mL}$ plastic beakers containing $100 \mathrm{~mL}$ dechlorinated water at $20{ }^{\circ} \mathrm{C}$ (room temperature) exposed to daylight for $6 \mathrm{~h}$. Subsequently, water was examined for presence of released cercariae under a dissecting microscope (Leica CLS 150X, magnification $\times 4-40$ ).

\section{Identification of cercariae}

The released cercariae were identified to type and genus level based on standard morphometric characters [1, 16-18]. In brief: Cercariae released from each snail were conserved in $70 \%$ ethanol and subsequently mounted on slides in glycerine-jelly (Fig. 1). Measurements $(\mu \mathrm{m})$ (forebody length and width, tail stem length and width, furca length, distance from apical end to ventral sucker) were done by use of a light microscope (Olympus, CH30PF200).

Species identification was based on PCR and sequencing of the gene locus ITS rDNA performed according to [7]. In brief: DNA was extracted from individual cercariae, isolated from each of 12 individual infected snails used in the experiment, using QIAamp ${ }^{\circledR}$ DNA Mini Kit from (QIAGEN). PCR was performed using the forward primer D1 (5'AGGAATTCCTGGTAA GTG CAAG'3) and the reverse primer BD2 (5'TAT

Table 1 Pulmonate snails collected at different time of the year in Ringen Lake with prevalence \% of Trichobilharzia and water temperature at time of collection

\begin{tabular}{lllll}
\hline Time/month & collected snails & $\begin{array}{l}\text { Trichobilharzia spp. } \\
\text { infected snails }\end{array}$ & $\begin{array}{l}\text { Non-infected snails } \\
\text { Prevalence\% } \\
\text { temperature } \\
\left({ }^{\circ} \mathbf{C}\right)\end{array}$ \\
\hline March & 42 & 0 & 42 & 0 \\
June & 91 & 0 & 91 & 0 \\
August & 226 & 22 & 204 & 1 \\
Total & 359 & 22 & 337 & $13-16$ \\
\hline
\end{tabular}




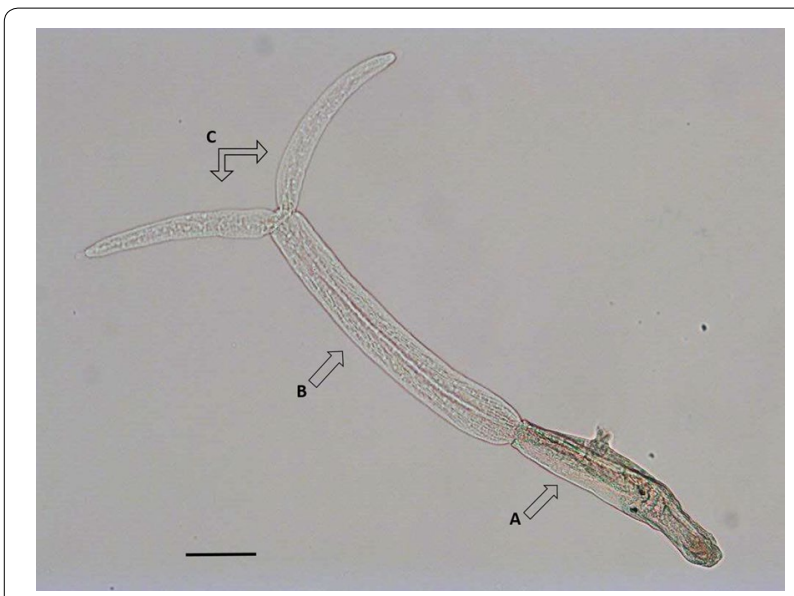

Fig. 1 Trichobilharzia szidati released from Lymnaea stagnalis snail at Ringen Lake, Roskilde, Denmark. a Frontal part of the cercaria with the part penetrating host skin, the ventral sucker for attachment of the cercaria pre-penetration and two eye-spots. b Tail. c Furca. Scale bar: $100 \mu \mathrm{m}$

GCTTAAATT CAGCGGGT'3) [19]. Reactions were run in a $\mathrm{T} 100^{\mathrm{TM}}$ Thermal Cycler (BioRad, Denmark) in a total reaction volume of $60 \mu \mathrm{L}$ containing: $1 \mu \mathrm{M}$ of each primer (Sigma-Aldrich, Denmark), $1 \mathrm{mM}$ of dNTP-mix (Life Technologies, Denmark), 1.25 units of BIOTAQ DNA polymerase (DNA Technology A/S, Denmark), $1.5 \mathrm{mM} \mathrm{MgCl}{ }_{2}$, and $6 \mu \mathrm{L} 10 \times$ PCR buffer and $2 \mu \mathrm{L}$ DNA template was added. Finally, DNase and RNase free water (Invitrogen ${ }^{\mathrm{TM}}$, Life Technologies, Denmark) was added to a final reaction volume of $60 \mu \mathrm{L}$. Sterile water was used as negative control. The following PCR protocol was used: initial denaturation at $94{ }^{\circ} \mathrm{C}$ for $5 \mathrm{~min}$, followed by 45 cycles of denaturation at $94^{\circ} \mathrm{C}$ for $30 \mathrm{~s}$, annealing at $57^{\circ} \mathrm{C}$ for $30 \mathrm{~s}$, and elongation at $72^{\circ} \mathrm{C}$ for $75 \mathrm{~s}$. After cycling, a final elongation step at $72{ }^{\circ} \mathrm{C}$ for 7 min was performed. The PCR products were visualized by gel electrophoresis and subsequently purified using Illustra ${ }^{\mathrm{TM}} \mathrm{GFX}^{\mathrm{TM}} \mathrm{PCR}$ and Gel band purification kit (VWR, Denmark). Fragments were sequenced by Macrogen Inc. (Seoul, South Korea) using the PCR primers used for the amplification process. Complete sequences were submitted to GenBank.

\section{Shedding experiments}

Trichobilharzia sp. infected snails were isolated in individual shedding beakers (diameter $55 \mathrm{~mm}$, depth $70 \mathrm{~mm}$, maximum water capacity $166 \mathrm{~mL}$ ) containing $100 \mathrm{~mL}$ dechlorinated water and used for determination of temperature and light effects on cercarial shedding. Snails were fed lettuce (Lactuca sativa) during the experiments.

\section{Enumeration of cercariae}

The number of cercariae released from each individual snail was quantified by daily exchange of incubation water (by moving the snail to a new plastic beaker contain similar water temperature). Three subsamples, each of $100 \mu \mathrm{L}$, from each snail beaker were taken with a pipette after stirring the water with released cercariae. Formaldehyde (4\%) were added to the subsamples to kill and fix the cercariae whereafter they were enumerated under the dissection microscope (Leica CLS $150 \mathrm{X}$ ). The total number of cercariae released per day was then calculated.

\section{Influence of temperature on cercarial shedding from snails}

Ten snails, each in its own beaker, were investigated at each temperature starting with $7{ }^{\circ} \mathrm{C}$ and after $24 \mathrm{~h}$ shedding the snails were incubated at $10^{\circ} \mathrm{C}$ and shedding was observed for $24 \mathrm{~h}$ and so forth. So the procedure was conducted with ten snails at five different temperatures: $7,10,15,22,27^{\circ} \mathrm{C}$ under a $15 \mathrm{~h}$ light: $9 \mathrm{~h}$ dark cycle (in thermostat controlled rooms). The cold light source was Cool white Philips LEDtube light 1200 mm UO 16 W 840 T8. Every $24 \mathrm{~h}$ water was exchanged (by moving the snail to a new plastic beaker with a similar water temperature) whereafter the exchanged water was examined under the dissecting microscope for enumeration of released cercariae. Experiments were conducted over five consecutive days.

\section{Influence of light on cercarial shedding from snails Light-dark cycle 12:12 h}

Four infected snails were incubated in individual shedding beakers at room temperature $\left(20^{\circ} \mathrm{C}\right)$ applying a $12 \mathrm{~h}$ light: $12 \mathrm{~h}$ dark cycle for 7 days (natural daylight regime). The number of released cercariae per snail per $12 \mathrm{~h}$ (each light and dark period) was noted.

\section{Constant light- dark and dark-light cycle 3:3 days}

Six infected snails were divided into two groups both kept at $20{ }^{\circ} \mathrm{C}$. Group one: each of three snails were incubated in individual shedding beakers placed under constant cold light (Cool white Philips LEDtube light $1200 \mathrm{~mm}$ UO 16 W 840 T8). Group two: each of three snails were kept under corresponding conditions but in constant darkness. Both groups were kept for 3 days whereafter illumination was reversed for three days (group one was placed in dark and group two in light). The number of released cercariae per snail per $24 \mathrm{~h}$ was noted.

\section{Phototaxy}

The experiment was conducted at $20{ }^{\circ} \mathrm{C}$ in a plastic chamber (dechlorinated water level $2 \mathrm{~mm}$ ) designed for this study. Dimensions were $40 \mathrm{~cm}$ length $\times 4 \mathrm{~cm}$ 
width $\times 4 \mathrm{~cm}$ height (wall thickness $2 \mathrm{~mm}$ ) (Fig. 2). The chamber was divided equally into two $20 \mathrm{~cm}$ zones. One was with black covering (dark zone), while the other zone was kept uncovered and illuminated (Fiber Optic Cold Light Source Kaltlichtquelle $150 \mathrm{~W}$ ). The chamber was placed and leveled under a Leica CLS 150X dissecting microscope for location and enumeration of cercariae. For each trial a total of 50 cercariae (1-6 h post-shedding in daylight at $20^{\circ} \mathrm{C}$ ) were applied by pipette directly into the borderline between the light and dark zones. The location and number of cercariae (presence in dark or light zone) were then recorded under the microscope after $60 \mathrm{~min}$ incubation.

\section{Life span of cercariae}

The life span of cercariae shed from infected snails at $20^{\circ} \mathrm{C}$ was examined at $5,10,15,20,25$ and $30^{\circ} \mathrm{C}$. A total of 18 shedding beakers, each containing 50-60 cercariae (1-6 h post-shedding) in a volume of $30 \mathrm{~mL}$ dechlorinated tap water, was used. Three beakers were kept and examined for living cercariae every $12 \mathrm{~h}$ at each of the specified temperatures (thermostat controlled rooms). Cool white Philips LED tube light $1200 \mathrm{~mm}$ UO 16W $840 \mathrm{~T} 8)$ was used for illumination. Immobility despite mechanical stimulation (touch with a needle) was used as criterion for death. Inactive cercariae were tested and recorded alive if they could be stimulated to move.

\section{Statistics}

We used a linear regression and Pearson's correlation test to investigate relationship between daily cercarial release at different temperatures. Differential cercarial shedding from infected snails kept at dark and light conditions were tested by use of Student's t-test. Likewise, location of cercariae in dark or light zones after $60 \mathrm{~min}$ incubation was compared by a Student's t-test. Differential survival according to temperature was evaluated using ordinary one-way ANOVA. Point-to-point lines are presented whereby time points with $10 \%$ cercarial survival can be determined (Fig. 7). These time points were plotted against temperature and linear regression performed (Fig. 7 insert). All the statistical analyses were performed using Graph Pad Prism version 7 and a 5\% probability level was used in all analyses.

\section{Results}

\section{Identification of snails}

All pulmonate snails collected in Ringen Lake were identified as Lymnaea stagnalis based on the characteristic features of the snail shell [15]. Their shell length and width (mean $\pm \mathrm{SD}$ ) were $44.6 \pm 6.3$ and $22.2 \pm 3.6 \mathrm{~mm}$, respectively. A total of 20 snails were used for further laboratory studies on temperature and light dependent shedding.

\section{Identification of cercariae}

All cercariae belonging to the genus Trichobilharzia shed from the investigated L. stagnalis were identified as Trichobilharzia szidati. Details of morphometric characters are provided in Table 2.

BLAST analyses were conducted with recovered sequences of the complete ITS1, 5.8S and ITS2 rDNA region at GenBank (NCBI). In all cases, a high identity (>99\%) was found with T. szidati GenBank accession no. GU233735 (Czech Republic).

\section{Influence of temperature on Trichobilharzia szidati cercarial shedding}

Cercarial emission from Lymnaea stagnalis snails was positively correlated to temperature. The daily shedding reached a mean of 3000 (SD 4000) cercariae per snail per day (minimum 20$)$ at $7{ }^{\circ} \mathrm{C}$ and a mean of $44,000(\mathrm{SD}$

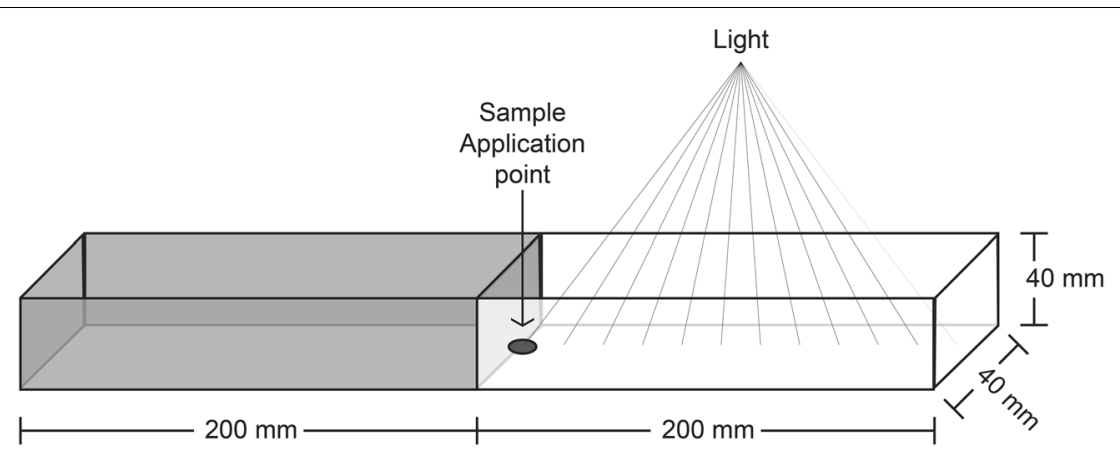

Fig. 2 Phototaxy plastic chamber used to determine effects of light on cercarial behavior, comprising two zones each with a length of $20 \mathrm{~cm}$. One zone was dark (covered with black plastic) and the other was uncovered and exposed to light. Illumination (cold light from a Leica microscope) was placed in the light end. Cercariae were placed by pipette on the border between zones (dark spot). The location of 60 cercariae was determined after 60 min incubation 
Table 2 Morphometric characters of cercariae released by $L$. stagnalis collected in Ringen Lake

\begin{tabular}{lc}
\hline & Mean \pm SD \\
\hline Total length & $952 \pm 86$ \\
Body length & $321 \pm 44$ \\
Body width & $54 \pm 5$ \\
Tail stem length & $386 \pm 49$ \\
Tail stem width & $40 \pm 8$ \\
Furca length & $254 \pm 19$ \\
Distance from apical & $225 \pm 33$ \\
body end to ventral sucker & \\
\hline
\end{tabular}

Dimensions of Trichobilharzia szidati cercariae. Mean and SD of a total of 12 specimens

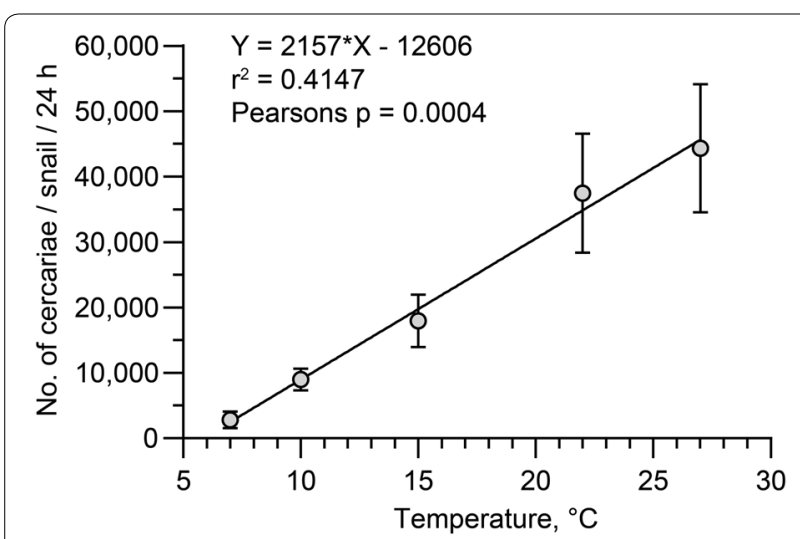

Fig. 3 Number of released cercariae of Trichobilharzia szidati per infected snail per day at 7, 10, 15, 22, $27^{\circ} \mathrm{C}$. Each point represents mean and SD of three snails ( $r^{2}$ : Pearson's coefficient of correlation)
30,000 ) with a maximum of 77,000 cercariae per snail per day at $27^{\circ} \mathrm{C}$. Accordingly, the mean numbers of cercariae released from one specimen of $L$. stagnalis daily were $37,000,18,000$, and 9000 at $22,15,10$ and $7{ }^{\circ} \mathrm{C}$, respectively (Fig. 3).

\section{Influence of light on cercarial shedding from L. stagnalis}

The cercarial shedding from $L$. stagnalis was examined in shifting light and dark periods (light dark cycle of $12: 12 \mathrm{~h}$ ) during 7 days in the laboratory at $20{ }^{\circ} \mathrm{C}$ but no clear release pattern was observed (Fig. 4). In contrast, when infected snails were kept constantly for 3 days, either in light or dark conditions, it was indicated that darkness inhibited shedding and light stimulated shedding under these circumstances (Fig. 5).

\section{Phototaxy}

Trichobilharzia szidati cercariae were attracted to light as significantly more cercariae ( $83 \%$ ) were recorded in the light zone as compared to the dark zone (17\%) (Fig. 6).

\section{Life span of Trichobilharzia szidati cercariae}

The cercarial life span was negatively correlated to temperature as the longevity decreased with increasing water temperature. The maximum life span recorded was 204 , $108,96,60,48$, and $36 \mathrm{~h}$ at $5,10,15,20,25$ and $30^{\circ} \mathrm{C}$, respectively (Fig. 7).

\section{Discussion}

The investigated Ringen Lake is an artificial lake which was established in 1977 for recreational purposes including bathing and other aquatic activities. The

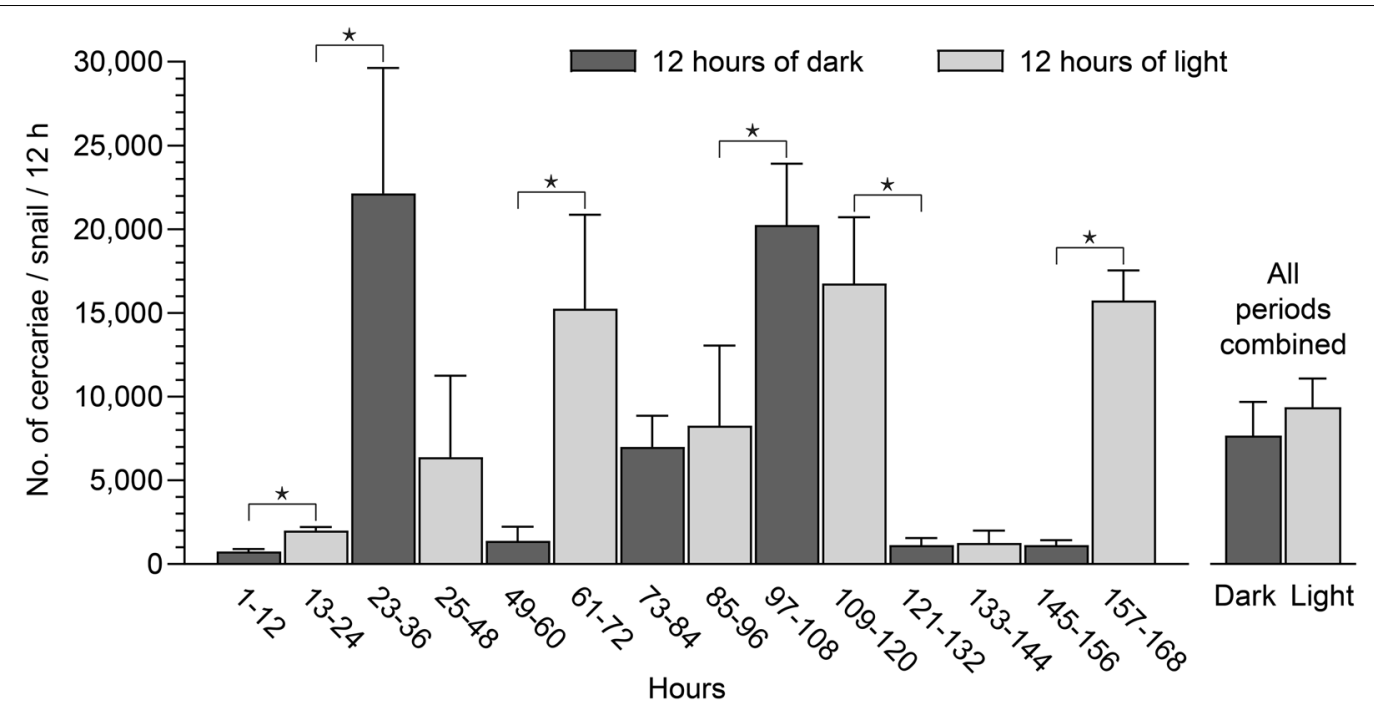

Fig. 4 Shedding of Trichobilharzia szidati cercariae from Lymnaea stagnalis snails in $12 \mathrm{~h}$ light and $12 \mathrm{~h}$ dark periods for 7 days. Each column represents mean and SD of three snails. Insets right: Average of 14 counts. *: $P^{<} 0.05$ 


\section{Light $\square$ Dark}
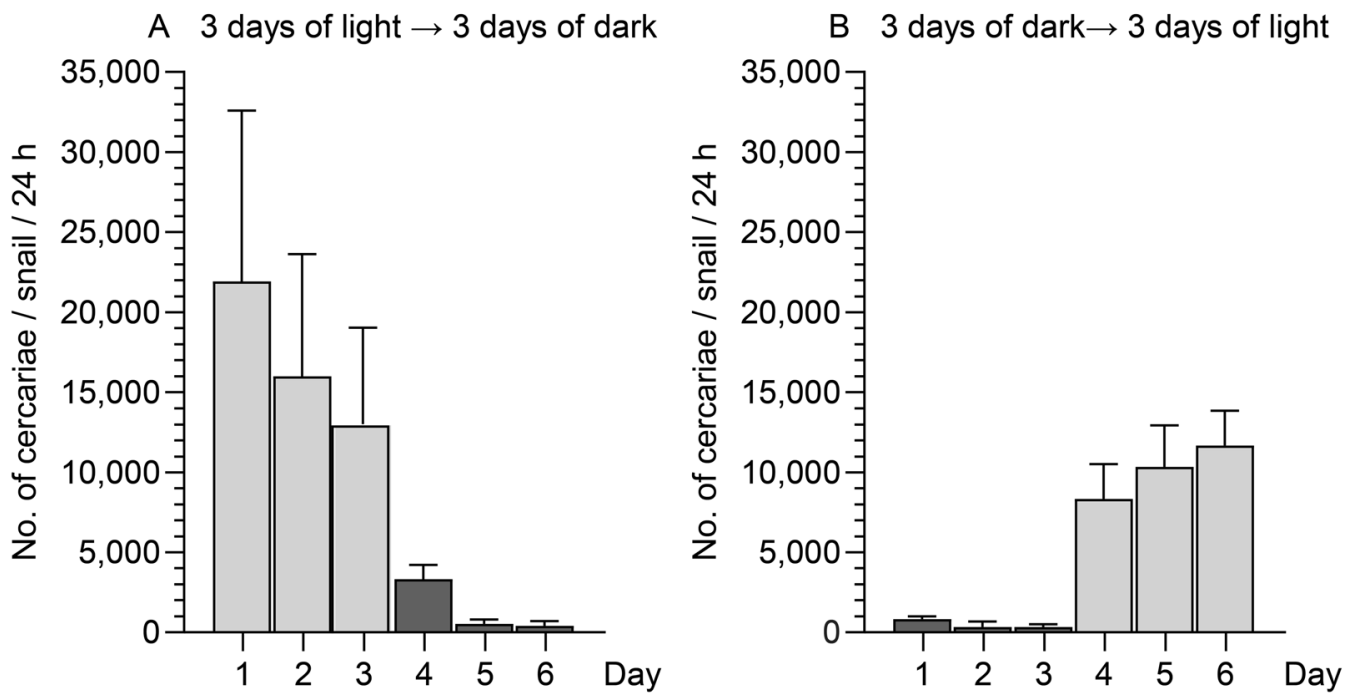

Fig. 5 Shedding of Trichobilharzia szidati cercariae per $24 \mathrm{~h}$ during six days. Each column represents mean and SD of shedding from six snails per day at $20^{\circ} \mathbf{C}$. a 3 days constant light or darkness, $\mathbf{b} 3$ days constant darkness or light

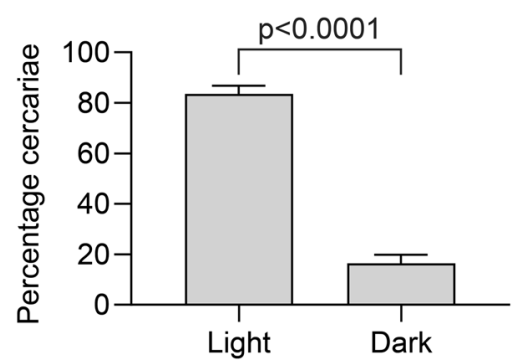

Fig. 6 Percentage of Trichobilharzia szidati cercaria in light and dark zones after 60 min incubation. Each column represents mean and SD of 20 measurements

public (children, adults, bathers, swimmers, anglers) is attracted to the shallow lake especially during warm summer periods. In the warm summer of 2018, cases of cercarial dermatitis (swimmer's itch) following contact with the lake were reported [3]. In order to describe the causes, provide a risk analysis and develop a preventive control strategy we investigated the occurrence of intermediate snail hosts, the identity of the causative pathogen and determined effects of temperature and light on shedding of infective cercariae from the host snails. This will provide a basis for evaluation of the infection risk during different seasons and during the day. The pulmonate snail $L$. stagnalis was the only snail species observed in the lake, and it is worthwhile to emphasize the uniqueness of the observation of only one species of Trichobilharzia in the investigated lake. Several species within the genus have previously been recorded in other natural Danish lakes $[6,7]$. It may be explained by the generally low biodiversity in the lake due to its short history and its artificial nature. When performing shedding experiments using these snails the only isolated parasite species, with a potential to elicit cercarial dermatitis, was T. szidati. A series of previous investigations have indicated that the release of infective cercariae and their behavior is dependent on temperature and/or light conditions $[20,21]$ and we therefore conducted laboratory studies on how could these ecological factors may influence the occurrence of infective cercariae in the lake. Field samplings from Ringen Lake, comprising several hundreds of snails, showed a seasonal occurrence of cercaria releasing snails, since only samplings in August-but not in March and June-were positive. It cannot be excluded that snails collected in March and June carried immature developing sporocysts (stage producing cercariae) [22] but in August the prevalence of shedding snails was $10 \%$, confirming presence of fully mature sporocysts. Temperature may affect development of all parasitic stages of the life cycle [23-25] whereby cercariae may occur earlier in warm summers. Under all circumstances, when sporocysts are mature, as in August 2019, we found that the shedding rate was correlated with temperature. The highest mean cercarial shedding $(44,000$ (SD 30,000) cercariae per day per snail), was recorded at $27{ }^{\circ} \mathrm{C}$ and the lowest mean rate (3000 (SD 4000) cercariae per snail per day) at $7{ }^{\circ} \mathrm{C}$. This temperature dependence is a general 


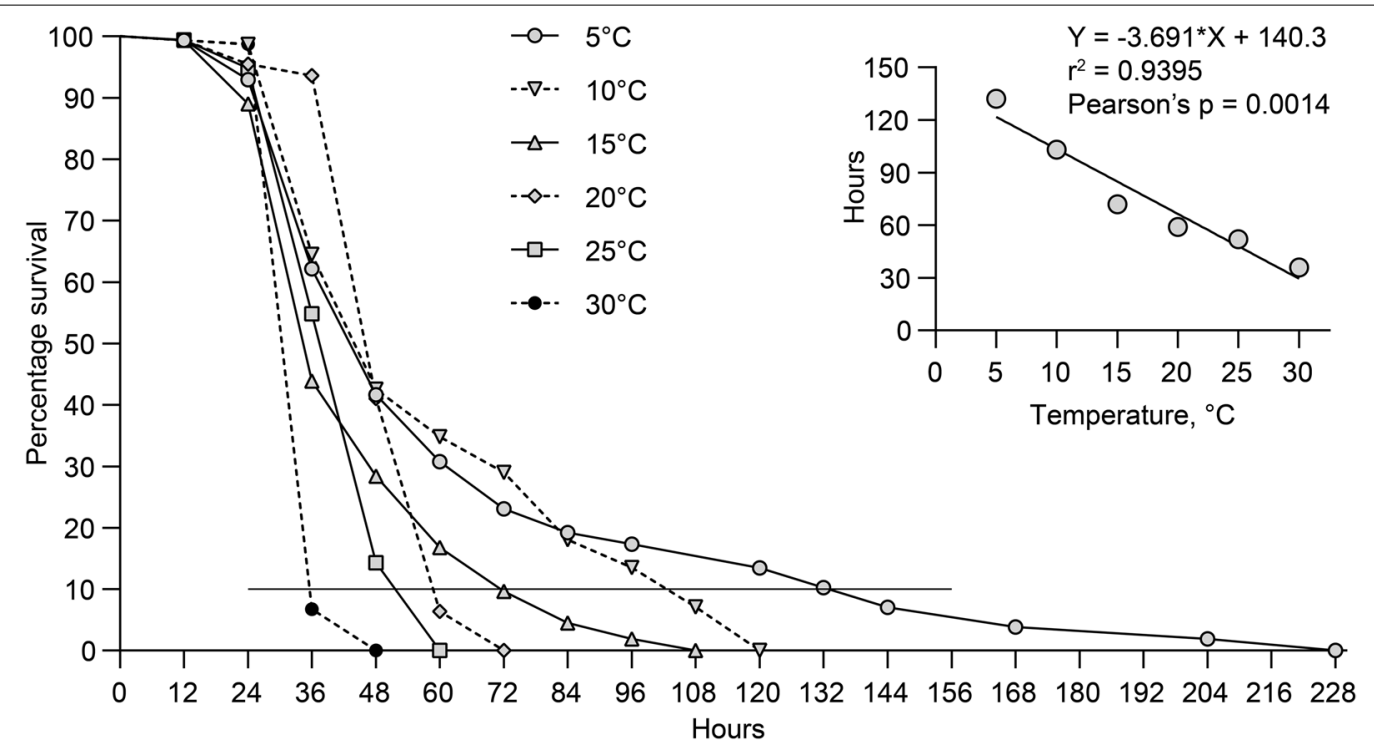

Fig. 7 Influence of temperature on the survival of Trichobilharzia szidati cercariae at 5 different temperatures during a $228 \mathrm{~h}$ period. Each point represent percentage of living cercariae out of 60 (percentage survival). Insert show correlation between survival time (h) and temperature. $r^{2}$ : Pearson's correlation coefficient

observation in trematode infected snails $[20,21]$ and explain why the infection risk is higher during warm periods when the public seek the lake. When evaluating infection risks the life span results indicate that cercariae survive several days after emergence from the snail. Even at high summer temperatures $\left(25\right.$ and $\left.30{ }^{\circ} \mathrm{C}\right)$ a part of the cercariae stay alive for both $48 \mathrm{~h}$ and $36 \mathrm{~h}$, respectively, and at lower temperatures they survive for more than eight days. Further, light is an abiotic factor with a possible effect on the infection level in lakes. We assessed the effect of the light-darkness cycle on release of cercariae and thereby potentially the infection risk. Diurnal shedding variations have been suggested as a synchronization of cercarial shedding with the daily activity patterns of the definitive host. Thus, ducks acting as the natural final host of bird schistosomes show activity patterns around sunrise and sunset [26] and synchronization of cercarial shedding with host activities can be explained as an adaptive behavior which can increase the probability of transmission [27]. Several examples are known from other schistosome parasitehost systems where some species emerge from snails at night (S.douthitti), midday (S. mansoni), later in the afternoon (S. japonicum), and some throughout the day (T. physellae) as cercarial release is related to behavioral patterns of the specific definitive host [28]. Emergence of T. szidati in German water bodies was also reported to occur during the first hours of light exposure [29]. In the present study $T$. szidati release was shown to be independent of light-darkness cycles unless the light or dark periods were of several days corresponding to previous other studies [30]. The inhibition of shedding in the laboratory setting with an extended dark period and stimulation of shedding in the light may indicate that light has an effect, although it has no importance for the infection risk in the Ringen Lake area. The behavior of the free-living cercarial stage may play a key role in the parasite transmission [31] but schistosomes differ with respect to light responses, with some species being less sensitive to light [32]. We noticed a positive phototactic behavioural pattern of $T$. szidati suggesting that the cercariae possess photoreceptors corresponding to previous findings in Trichobilharzia physellae [33]. Trichobilharzia ocellata was reported to respond to light with complex behaviors and not always showing phototropism [34]. Positive phototaxy may be considered part of a life cycle strategy increasing the probability to find a host and complete the life cycle. In the investigated Ringen Lake it may have implications for the risk analysis that cercariae concentrate in upper water layers during daytime when bathers visit the lake.

The longevity of $T$. szidati cercariae is temperature dependent as cercariae kept at $5{ }^{\circ} \mathrm{C}$ survived more than eight days while they died after $48 \mathrm{~h}$ at $30{ }^{\circ} \mathrm{C}$. This progressive decrease in the life span of the free-living cercariae corresponds to findings in other trematode species. The negative correlation between lifespan and temperature is probably due to the temperature dependent usage of the stored energy reserves (glycogen) in the parasite $[20,21,35]$. Ringen Lake can serve as a suitable 
model system for establishing risk analysis strategies with regard to cercarial dermatitis. When providing an overall assessment of the risk associated with aquatic activities (bathing, swimming, fishing) in Ringen Lake, our investigations point to a low risk of infection during spring and early summer (March-June) due to no or low shedding of infective T. szidati cercariae from the resident snails. When the developing sporocysts in the snails mature and release cercariae in late summer, as seen in August, the risk of infection is high. During our samplings 100 to 200 snails were easily collected within $1 \mathrm{~h}$ suggesting a total snail population in the lake of several thousand individuals. As the prevalence was $10 \%$ and each snail has a potential to shed up to 77,000 cercariae per day in a small lake with a water depth below $1.5 \mathrm{~m}$ and surface area of less than $10,000 \mathrm{~m}^{2}$ the concentration of cercariae must be high. Survival of the snail and its shedding capacity are important epidemiological parameters and should be included in future risk assessments. This may further be emphasized by finding that the cercarial life span (for at least $10 \%$ of the cercariae) survive $60 \mathrm{~h}$ post-shedding at $20{ }^{\circ} \mathrm{C}$ and $36 \mathrm{~h}$ at $25^{\circ} \mathrm{C}$ whereby a steady increase of the pathogen concentration is expected. The infection pressure may be further elevated by the finding that cercariae due to their positive phototaxy concentrate in the surface water when the public seeks the lake during daytime. Therefore, during the summer period any person entering the lake is likely to get into contact with the parasite and is at potential risk of developing symptoms of cercarial dermatitis. It is therefore recommended to establish a monitoring program for Trichobilharzia cercariae in the lake. This can be done by weekly collection of snails and performing shedding experiments as described here. It is known that snail size influence shedding capacity [14, $36,37]$. In our study, the experimental snails had a mean shell height of 44.6 (SD 6.3) $\mathrm{mm}$ it is worthwhile to monitor snail size and survival for future risk analyses of the lake.

\section{Conclusion}

The present study used the lake Ringen sø as a model to evaluate the risk of Trichobilharzia infection (cercarial dermatitis, swimmer's itch) in a lake frequented by the public. We demonstrated that infection is caused by cercariae of the bird schistosome T. szidati released from the pulmonate snail L. stagnalis. Important parameters such as the release (shedding), behavior and life span of the infective larvae are light and temperature dependent. Overall assessment of the risk associated with aquatic activities, is low during spring and early summer (MarchJune) due to no or a low shedding rate of $T$. szidati cercariae. In contrast, in late summer the risk of infection is high all day. Regular sampling of snails associated with shedding procedures throughout the year are recommended. From early summer weekly samplings of snails and determination of their infection status may assist determination of the infection risk for the public.

\section{Acknowledgements}

The authors would like to thank the staff of the Aquatic Pathobiology Laboratory for their patience and help during the snail investigations.

\begin{abstract}
Authors' contributions
$A A, P K$ and $K B$ designed the study in collaboration with $A B$. AA and PK collected the samples and performed the laboratory and data analyses. $\mathrm{KB}$ and $A B$ coordinated the study. All authors interpreted the results. $A A, A B$ and $K B$ drafted the manuscript. All authors read and approved the final manuscript.
\end{abstract}

\section{Funding}

This study was partly funded by Odense Universitets hospital and the University of Copenhagen.

\section{Availability of data and materials}

The datasets analysed during the current study are available from the corresponding author on request.

\section{Ethics approval and consent to participate}

This study did not require approval from authorities, organisations or ethics committees.

\section{Consent for publication}

Not applicable.

\section{Prior publication}

Data have not been published previously.

Competing interests

The authors declare that they have no competing interests.

\section{Author details}

${ }^{1}$ Laboratory of Aquatic Pathobiology, Department of Veterinary and Animal Sciences, Faculty of Health and Medical Sciences, University of Copenhagen, Stigbøjlen 7, 1870 Frederiksberg C, Denmark. ${ }^{2}$ Department of Dermatology and Allergy Centre, Odense University Hospital, J.B. Winsløws Vej 4, 5000 Odense C, Denmark.

Received: 21 May 2020 Accepted: 9 September 2020

Published online: 15 September 2020

References

1. Horak P, Kolaova L, Adema C. Biology of the schistosome genus Trichobilharzia. Adv Parasitol. 2002;52:155-233.

2. Skirnisson K, Aldhoun JA, Kolarova L. A review on swimmer's itch and the occurrence of bird schistosomes in Iceland. J Helminthol. 2009;83:165-71.

3. Tracz ES, Al-Jubury A, Buchmann K, Bygum A. Outbreak of swimmer's itch in Denmark. Acta Derm Venereol. 2019;99:1116-20.

4. Marszewska A, Cichy A, Heese T, Zbikowska E. The real threat of swimmers' itch in anthropogenic recreational water body of the Polish Lowland. Parasitol Res. 2016;115:3049-56.

5. Buchmann K, Larsen A, Bresciani J. Snyltere angriber badegæster Aktuel Nat. 2004;1:8-10.

6. Larsen A, Bresciani J, Buchmann K. Increasing frequency of cercarial dermatitis at higher latitudes. Acta Parasitol. 2004;49:217-21.

7. Christiansen AO, Olsen A, Buchmann K, Kania PW, Nejsum P, Vennervald BJ. Molecular diversity of avian schistosomes in Danish freshwater snails. Parasitol Res. 2016;115:1027-37.

8. Soleng A, Mehl R. Geographical distribution of cercarial dermatitis in Norway. J Helminthol. 2011;85:345-52.

9. Thors C, Linder E. Swimmers' itch in Sweden. Helminthologia. 2001;38:244. 
10. Appleton CC, Lethbridge RC. Schistosome dermatitis in the swan estuary, western Australia. Med J Austral. 1979;1:141-4.

11. Ley Vesque B, Giovenazzo P, Guerrier P, Laverdire D, Prud'home H. Investigation of an outbreak of cercarial dermatitis. Epidemiol Infect. 2002;129:379-86.

12. Valdovinos C, Balboa C. Cercarial dermatitis and lake eutrophication in south-central Chile. Epidemiol Infect. 2008;136:391-4.

13. Pietrock M, Marcogliese DJ. Free-living endohelminth stages: at the mercy of environmental conditions. Trends Parasitol. 2003:19:293-9.

14. Thieltges DW, de Montaudouin X, Fredensborg B, Jensen KT, Koprivnikar J, Poulin R. Production of marine trematode cercariae: a potentially overlooked path of energy flow in benthic systems. Mar Ecol Prog Ser. 2008:372:147-55.

15. Glöer P. Die Süsswassergastropoden Nord- und Mitteleuropas. Germany: ConchBooks; 2., neu bearb. Aufl. edition; 2002.

16. Wesenberg-Lund C. Contributions to the development of the Trematoda Digenea. Part II. The biology of the freshwater Cercariae in Danish freshwaters. Memoires de 1'Academic Royale des Sciences et des Lettres de Danemark Section des Sciences. 1934;5:1-223.

17. Schell SC. How to know the trematodes. University of Idaho: WMC Brown Co., Publishers; 1970.

18. Cichy A, Zbikowska A. Atlas of Digenea developmental stages. The morphological characteristics and spread within the populations of freshwater snails from the Brodnickie Lakeland. Poland: Wydawnictwo Naukowe UMK, Torun; 2016.

19. Galazzo DE, Dayanandan S, Marcogliese DJ, McLaughlin JD. Molecular systematics of some North American species of Diplostomum (Digenea) based on rDNA-sequence data and comparisons with European congeners. Can J Zool. 2002;80:2207-17.

20. Evans NA. The influence of environmental temperature upon transmission of the cercariae of Echinostoma liei (Digenea: Echinostomatidae). Parasitology. 1985;90:269-75.

21. Lyholt HCK, Buchmann K. Diplostomum spathaceum: effects of temperature and light on cercarial shedding and infection of rainbow trout. J Dis Aquat Organ. 1996;25:169-73.

22. Graham AL. Effects of snail size and age on the prevalence and intensity of avian schistosome infection: relating laboratory to field studies. J Parasitol. 2003;89:458-63.

23. Mouritsen KN. The Hydrobia ulvae-Maritrema subdolum association: influence of temperature, salinity, light, water-pressure and secondary host exudates on cercarial emergence and longevity. J Helminthol. 2002;76:341-7.

24. Mas-Coma S, Valero MA, Bargues MD. Climate change effects on trematodiases, with emphasis on zoonotic fascioliasis and schistosomiasis. Vet Parasitol. 2009;163:264-80.
25. Morley NJ, Lewis JW. Thermodynamics of cercarial development and emergence in trematodes. Parasitology. 2013;140:1211-24.

26. Sauter A, Korner P, Fiedler W, Jenni L. Individual behavioural variability of an ecological generalist: activity patterns and local movements of Mallards Anas platyrhynchos in winter. J Ornithol. 2011;153:713-26.

27. Combes C, Fournier A, Mone H, Theron A. Behaviours in trematode cercariae that enhance parasite transmission: patterns and processes. Parasitol. 1994;109(Suppl):S3-13.

28. Théron A. Early and late shedding patterns of Schistosoma mansoni cercariae: ecological significance in transmission to human and murine hosts. J Parasitol. 1984;70:652-5.

29. Soldanova M, Selbach C, Sures B. The early worm catches the bird? Productivity and patterns of Trichobilharzia szidati cercarial emission from Lymnaea stagnalis. PLoS ONE. 2016;11:e0149678.

30. Rees G. Some observations and experiments on the biology of larval trematodes. J Parasitol. 1931;23:428-40.

31. Haas W. Host finding-A physiological effect: Springer-Verlag. Berlin: Heidelberg, New York, Tokyo; 1988.

32. Brachs S, Haas W. Swimming behaviour of Schistosoma mansoni cercariae: responses to irradiance changes and skin attractants. Parasitol Res. 2008;102:685-90

33. McMullen DB, Beaver PC. Studies on schistosome dermatitis. IX. The life cycles of three dermatitis-producing schistosomes from birds and a discussion of the subfamily Bilharziellinae (Trematoda : Schisto-somatide). Am J Hyg. 1945;42:128-54.

34. Haas W. Physiological analysis of cercarial behavior. J Parasitol. 1992;78:243-55.

35. Lawson JR, Wilson RA. The survival of the cercariae of Schistosoma mansoni in relation to water temperature and glycogen utilization. Parasitol. 1980;81:337-48.

36. Poulin R. Global warming and temperature-mediated increases in cercarial emergence in trematode parasites. Parasitol. 2006;132:143-51.

37. Marszewska A, Strzala T, Cichy A, Dabrowska GB, Zbikowska E. Agents of swimmer's itch-dangerous minority in the Digenea invasion of Lymnaeidae in water bodies and the first report of Trichobilharzia regenti in Poland. Parasitol Res. 2018;117:3695-704.

\section{Publisher's Note}

Springer Nature remains neutral with regard to jurisdictional claims in published maps and institutional affiliations.
Ready to submit your research? Choose BMC and benefit from:

- fast, convenient online submission

- thorough peer review by experienced researchers in your field

- rapid publication on acceptance

- support for research data, including large and complex data types

- gold Open Access which fosters wider collaboration and increased citations

- maximum visibility for your research: over $100 \mathrm{M}$ website views per year

At BMC, research is always in progress.

Learn more biomedcentral.com/submissions 